\title{
A Review on Parameters Identification Methods for Asynchronous Motor
}

\author{
Xing Zhan,Guohui Zeng,Jin Liu, Qingzhen Wang,Sheng Ou \\ College of Electronic and Electrical Engineering \\ Shanghai university of engineering science \\ Shanghai, China
}

\begin{abstract}
The decoupling of excitation current and torque current is realized by Vector control so that the speed regulating performance of asynchronous motor is comparable with that of dc motor. The control precision is directly affected by accuracy of parameter identification in asynchronous motor. In this paper, based on the existing literatures, the existed parameters identification methods both online and offline are analyzed and compared, and the advantages and disadvantages of the various algorithms are listed it tables. Therefore, a comprehensive identification method of adjustable model which makes the least square method as adaptive method of model reference is presented. Finally, the outlook of developing direction for parameters identification of asynchronous motor are put forward to.
\end{abstract}

Keywords-Vector control; Parameters identification; MRAS; the least square method

\section{INTRODUCTION}

Since the vector control was presented by Felix Blaschks, the ac speed regulating performance of asynchronous motor is comparable with that of dc motor. Vector control which is through the mathematical formula and the matrix transformation to make decoupling between the excitation current and torque current of asynchronous motor [1], and the control performance of asynchronous motor is enhanced greatly by a similar dc motor control method. Now, the parameters identification methods of asynchronous motor are mainly off-line identification and online identification. Because of the basic parameter of vector control can be provided and the operation is simple, the off-line identification is used most. But in the process of the motor operation, the stator resistance $\left(R_{s}\right)$ and rotor resistance $\left(R_{\mathrm{r}}\right)$, and the time constant of Motor rotor $\left(T_{\mathrm{r}}=L_{\mathrm{r}} / R_{r}\right)$ are influenced by the change of environment, such as the change of temperature, air humidity, high pressure, dust, and so on. The change of the time constant of rotor is affected by the change of resistance ${ }^{[2]}$, which leads to magnetic field orientation is not accurate, and a better decoupling will not be produced between the excitation current and torque current of asynchronous motor. Finally, inaccuracy and deflection are emerged, and industrial production is also affected.

Off-line identification techniques [3]: (a) on one hand, the motor speed can be made to close to the synchronous speed by the traditional no-load experiment; On the other hand, the motor speed can be made to be zero by locked-rotor experiment. (b) The motor parameters can be identified through the data of motor structure. (c) Different voltage are injected to motor based on a converter, the motor parameters can be identified by the motor to inspire different voltage. (d)A mathematical program is provided by least-squares, and a fitting curve is gain, which is about the fitting of minimum variance sense and an experimental data of completely measuring. Then the result of identification is obtained.

The excitation component and torque component of stator current are decoupled by formula (1) and formula (2). The ac speed regulating performance of asynchronous motor is compared with dc motor speed control. asynchronous motor's operation, motor parameters are easily influenced by environment. But the off-line identification cannot solve this problem absolutely. In order to control the precision of motor, the online identification of asynchronous motor is required.

At present, there exist 4 types of online identification techniques: (a) recursive least squares ${ }^{[4-5]}$. The estimated value of objective function is corrected continuously, and the parameter is estimated step by step until the satisfied parameter value is gained. (b) The extended Calman filter ${ }^{[6]}$ is recursive estimation method ${ }^{[7]}$. The estimated value of current state is calculated through the estimated value at the state of a moment before and the observed value of current, and this method is used in linear stochastic systems ${ }^{[8-9]}$.(c)MRAS is used to identified the motor parameter, and a suitable adaptive law is found $^{[10-11]}$. The output's error between the reference models without identified parameters and the adjustable models with Different voltage are injected to motor based on a converter is a more reliable method than other off-line identification method. This method has many advantages, such higher recognition efficiency, higher precision, more convenient, and so on. The electronic resistance $\left(R_{s}\right)$, leakage inductance of stator and rotor $(\sigma)$, rotor resistance $\left(R_{\mathrm{r}}\right)$, and the mutual inductance $\left(L_{\mathrm{n}}\right)$ could be identified through this method. The time constant of rotor $\left(T_{r}=L_{r} / R_{r}\right)$ can be deduced by the above identified parameters. Then, the stator current of motor is decomposed into torque component $\left(i_{\mathrm{st}}\right)$ and excitation component $\left(i_{\mathrm{sa}}\right)$ via the mathematical model of vector control and coordinate transformation.

This work is supported by the Natural Science Foundation of Shanghai under Grant No.14ZR1418400 and the Innovation Foundation of Shanghai Education Commission under Grant No.13YZ111 and the Innovation Foundation of SUES under Grant No.E1-0903-14-01041 


$$
\begin{aligned}
& T_{\mathrm{e}}=\frac{\mathrm{p}_{\mathrm{n}} L_{\mathrm{m}}}{L_{\mathrm{r}}} \dot{\mathrm{i}}_{\mathrm{st}} \psi_{\mathrm{r}} \\
& \psi_{\mathrm{r}}=\frac{L_{\mathrm{m}}}{T_{\mathrm{r}} P+1} \dot{\mathrm{i}}_{\mathrm{sm}}
\end{aligned}
$$

identified parameters tends to zero finally ${ }^{[12]}$. Then the motor's parameters are identified $^{[13]}$. (d) The algorithms of artificial and intelligent identification is used to simulate natural biological systems, and totally dependent on its instinct to optimize the existence to adapt to the environment ${ }^{[14]}$.

\section{THE FACTORS OF PARAMETERS}

The parameters are in change for moment in the mathematical model of asynchronous motor and effected easily by factors .with changes of environmental factors and asynchronous motor, the parameters is changing. The parameters mainly contain stator resistance $\left(R_{s}\right)$, rotor resistance $\left(R_{r}\right)$, stator inductance $\left(L_{s}\right)$, rotor inductance $\left(L_{r}\right)$, and the mutual inductance between stator and rotor $\left(L_{\mathrm{s}}\right)$. The main factors of the change of the asynchronous motor running parameters are shown in table 1 :

TABLE I. THE MAIN FACtors OF THE CHANGE OF THE ASYNCHRONOUS MOTOR RUNNING PARAMETERS

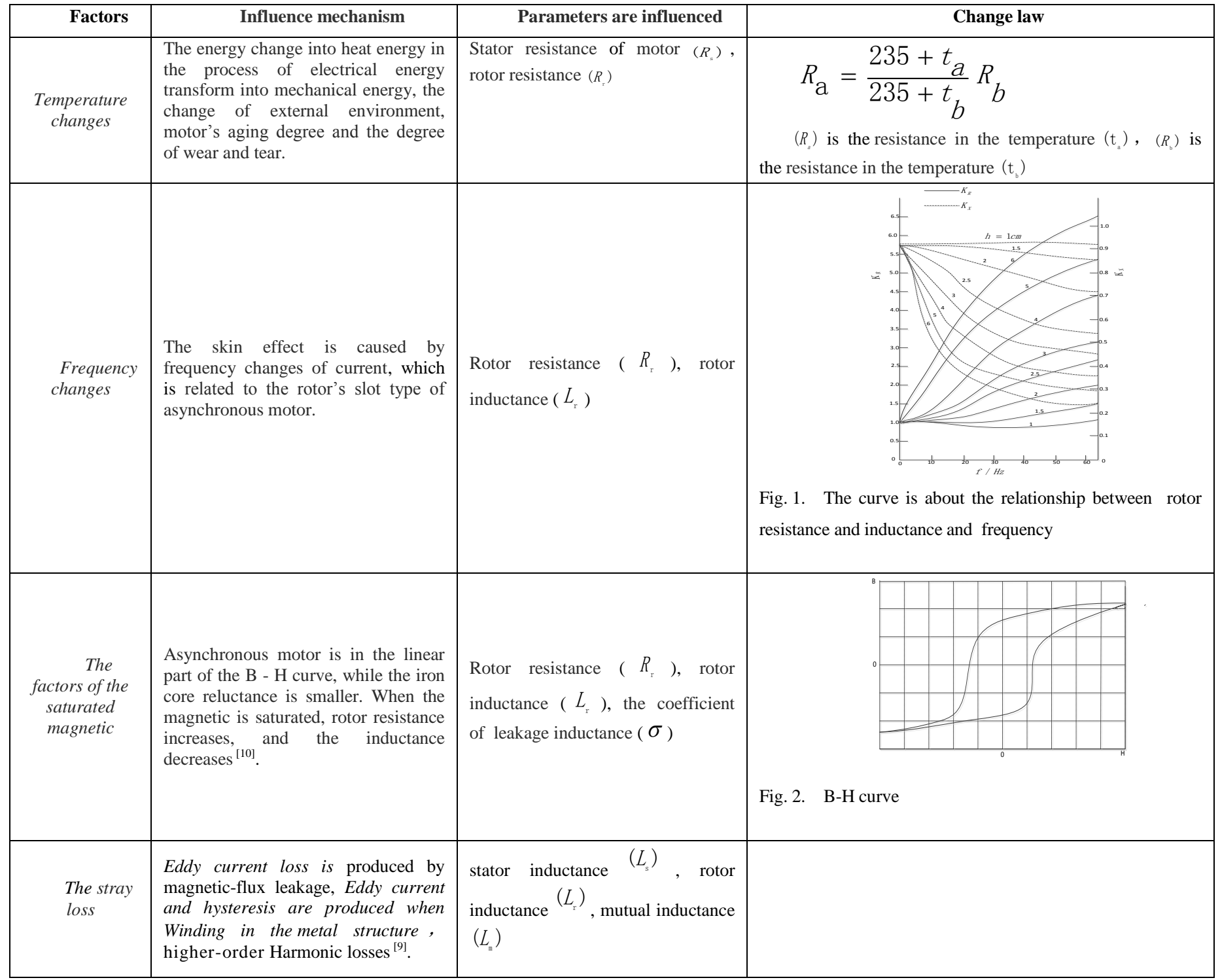




\section{THE IDENTIFICATION METHOD OF PARAMETER}

\section{A. The off-line identification method}

Currently, the off-line identification method is studied in the world and advantages and disadvantages of each method are shown in table 2.

TABLE II. ADVANTAGES AND DisAdVANTAGES OF THE OFF-LinE IDENTIFICATION METHOD

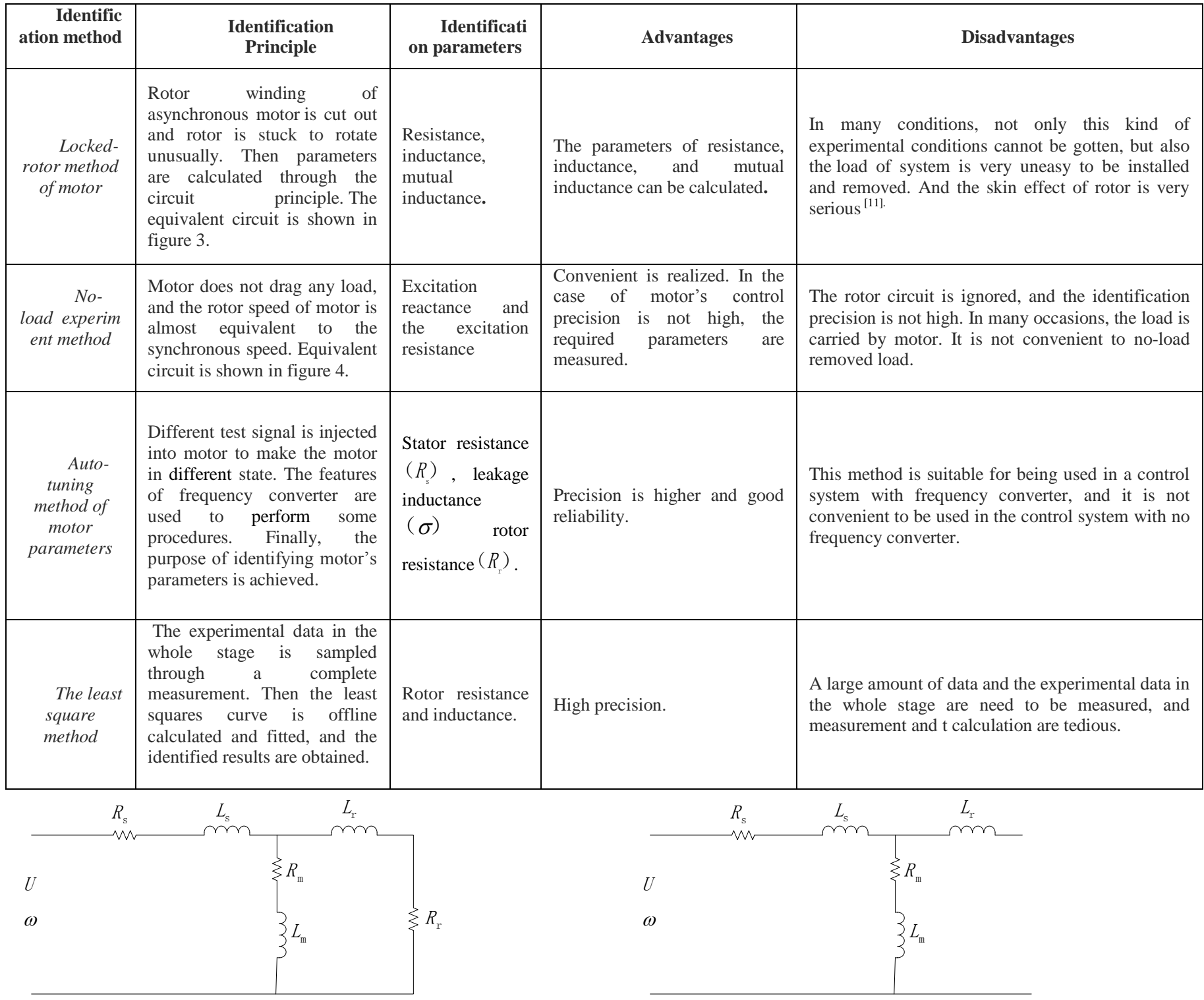

Fig. 3. The equivalent figure of motor cutting-out

\section{B. Online identification method}

The above off-line identification methods are the identification that in the case of motor no-load or in a moment the motor is changing with temperature and environment in the operation process. In a high-precision control system, the off-
Fig. 4. The equivalent figure of motor no-load

line identification cannot meet the requirements. Thus, the parameters are required to be identified online and identified at every moment. Online identification method is shown in table 3. 
TABLE III. THE ONLINE IDENTIFICATION METHOD

\begin{tabular}{|c|c|c|c|c|}
\hline $\begin{array}{c}\text { dentification } \\
\text { method }\end{array}$ & $\begin{array}{c}\text { Identification } \\
\text { principle }\end{array}$ & $\begin{array}{c}\text { Identification } \\
\text { parameters }\end{array}$ & Advantages & Disadvantages \\
\hline $\begin{array}{l}\text { The extended } \\
\text { Calman filter }\end{array}$ & $\begin{array}{l}\text { The state equations of motor is } \\
\text { used directly. The parameters } \\
\text { which need to be identified and } \\
\text { states are set as quantities of } \\
\text { augmented state. The optimal } \\
\text { estimation of the state is given } \\
\text { solving riccati equations in } \\
\text { online }^{\text {[81. }}\end{array}$ & $\begin{array}{l}\text { Rotor resistance, } \\
\text { mutual inductance, } \\
\text { flux linkage }\end{array}$ & $\begin{array}{l}\text { With high identified } \\
\text { precision and more } \\
\text { parameters. And other } \\
\text { unpredictable state can be } \\
\text { estimated. Itself has } \\
\text { filtering effect and can } \\
\text { reduce some interference }{ }^{\mathrm{g} g \mathbf{l}} \\
\text {. }\end{array}$ & $\begin{array}{l}\text { The algorithm is } \\
\text { complex and good } \\
\text { performance of } \\
\text { processor is required }\end{array}$ \\
\hline$M R A S$ & $\begin{array}{l}\text { The actual running of motor is } \\
\text { used as the reference model, and } \\
\text { the state observation equation of } \\
\text { motor is used as the adjustable } \\
\text { model. Motor's parameters of } \\
\text { the adjustable model are } \\
\text { corrected in real time by some } \\
\text { measurable deviation }\end{array}$ & $\begin{array}{l}\text { Rotor resistance, } \\
\text { stator resistance, } \\
\text { mutual inductance. }\end{array}$ & $\begin{array}{l}\text { A small amount of } \\
\text { calculation and high } \\
\text { precision. }\end{array}$ & $\begin{array}{l}\text { Reference model is } \\
\text { difficult to be } \\
\text { determined }\end{array}$ \\
\hline $\begin{array}{l}\text { The improved } \\
\text { least square } \\
\text { method }\end{array}$ & $\begin{array}{l}\text { The experimental data in the } \\
\text { whole stage is sampled through } \\
\text { a complete measurement. Then, } \\
\text { the least squares curve is } \\
\text { calculated offline and fitted, and } \\
\text { the identification results are } \\
\text { obtained. }\end{array}$ & $\begin{array}{l}\text { Resistance, } \\
\text { inductance, time } \\
\text { constant of rotor. }\end{array}$ & $\begin{array}{l}\text { High precision and good } \\
\text { reliability. Both online and } \\
\text { offline identification. }\end{array}$ & $\begin{array}{l}\text { It is Sensitive to noise } \\
\text { of measurement and } \\
\text { fluctuation of speed. } \\
\text { The estimated value } \\
\text { exists multi solutions } \\
\text { and deviation } \\
\text { problems owing to } \\
\text { the singularity of } \\
\text { structure matrix. }\end{array}$ \\
\hline $\begin{array}{c}\text { Intelligent } \\
\text { algorithm[15] }\end{array}$ & $\begin{array}{l}\text { Neural network and genetic } \\
\text { algorithm are included in this } \\
\text { method }{ }^{[16]} \text {. The former makes } \\
\text { the function value of error to be } \\
\text { minimized } \\
\text { learning system's Input and } \\
\text { output. The latter is a kind of } \\
\text { random search algorithm, which } \\
\text { can simulates the natural } \\
\text { evolution }{ }^{[17]} \text {. }\end{array}$ & $\begin{array}{l}\text { Resistance } \\
\text { inductance }\end{array}$ & The precision is very high. & $\begin{array}{l}\text { The calculation is so } \\
\text { huge and the } \\
\text { requirement for } \\
\text { processor is relatively } \\
\text { high. }\end{array}$ \\
\hline
\end{tabular}

\section{COMPREHENSIVE IDENTIFICATIONSYSTEM}

According to the analysis and study of existing literature, the single identification method has defects more or less.

A kind of method that both off-line identification and online identification are put forward by author based on existing literatures. The method is combined with model reference adaptive and improved least square method. The adjustable model is constructed by the improved least square method, and the least error is made to be minimized between the reference model and the adjustable model.

\section{A. The principle of model reference adaptive}

THE PRINCIPLE OF MODEL REFERENCE ADAPTIVE IS SHOWN IN FIGURE 5.

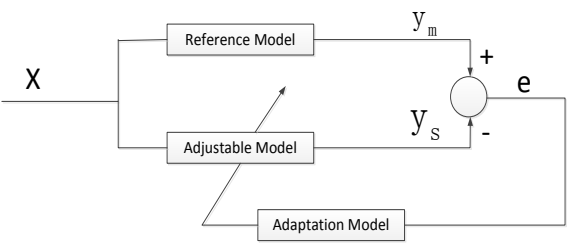

Fig. 5. Principle of model reference adaptive
This system has the same external input(X), while the (X) is input to the reference model and the adjustable model. $\left(y_{n}\right)$ and $\left(y_{s}\right)$ are the output of the reference model and the adjustable model. Finally, the result of $e=\left|y_{z}-y_{s}\right|$ is calculated to be minimized or zero through the adaptive adjustment. The design of adaptive control mainly includes:

1) The optimization theory of partial parameters. The structured distance between the reference model and the adjustable model is defined, or two times performance index of state distance. The method of parameter optimization is used to determine the adjustment of parameters of the controller. Rules make the adjustable model closer to reference model to achieve the purpose of identifying parameters.

2) Popov super stability theory. Firstly, the model reference adaptive system should be transformed into equivalent nonlinear time-varying feedback system. Namely, the system is formed by a linear forward link and a nonlinear feedback link. A suitable law of adaptive control is gotten 
under the guarantee of meeting the two conditions. This makes the whole nonlinear system is stable, which can ensure the system error tends to zero and achieve the purpose of adaptive control.

\section{B. B. The least square method}

A linear relationship exists between the variables ( $\mathrm{y}$ ) and one dimensional variable $\mathrm{x}=\left(\mathrm{x}_{1}, \mathrm{x}_{2}, x_{3} \ldots x_{n}\right)$, namely:

$$
y=c_{1} x_{1}+c_{2} x_{2}+c_{3} x_{3}+\ldots+c_{n} x_{n}
$$

The value ( $C$ ) is estimated based on the observed values ( $y)$ and $(x)$ in different time. This method requires repeated computation under the need of update data, this problem is solved by recursive least squares method. A new set of data don't need to be added and calculated again, and the amount of calculation is reduced greatly. The basic idea of recursive least square method is: the new estimate value $=$ the old estimate value + correction term. So that $\mathrm{y}=\theta_{\mathrm{i}} \mathrm{x}$ and $\mathrm{e}=\mathrm{y}_{\mathrm{m}}-\theta_{\mathrm{i}} \mathrm{x}$ is its minimum.

\section{CONCLUSION}

Through analyzing and concluding the existing literatures, Conclusions can be gotten as follows:

1) As shown by the table 1, the rotor resistance of asynchronous motor is changed mostly by the environmental factors. As shown by the formula (1) and formula (2), the rotor flux linkage is changed directly by the change of rotor resistance. Then, the decoupling of rotor flux linkage is not sufficient. If a certain control accuracy is required by a control system, a control method which main identifies rotor resistance can be chosen.

2) Offline identification method has many kinds of classes. Being compared with the locked-rotor method of motor no-load experiment method and the least square method,auto-tuning method of motor parameters is used most widely, the technology is most mature, and the identification accuracy is more accurate and reliable.

3) The system which requires high precision of identification, low cost and reliable performance and easy to implement, the least squares method is a better method, because this method can not only realize the off-line identification but also realize the online identification.

4) As to the control system which very high accuracy of identification, intelligent algorithm can be used as the focus of future research methods. This method has the very good control precision.

With the rapid development of the economic in China, the motor's control technology with high precision is widely used in all kinds of industrial fields. The higher requirements for the identification accuracy of asynchronous motor is put forward. At present, China is still relatively backward in terms of manufacturing and control of asynchronous motor. Especially the gap from Western countries in processor manufacturing is large. How to make the motor control more accurate, which requires higher parameter identification. Although the general industrial production requirements can be satisfied by the identification method of existing parameters, it is not enough in some high precision control system. In genetic algorithm, genetic algorithm and neural network algorithm are continuous optimization and find out the optimal solution, which needs higher requirements for the processor to be put forward. Therefore, the intelligent algorithm has a broad prospect in the future and it can be developed from two aspects. On one hand, the intelligent algorithm could be improved ${ }^{[18-19]}$. The algorithm is simple and high precision of parameter identification could be achieved. On the other hand, the performance of processor could be improved so that the processor speed is faster and cheaper.

\section{REFERENCES}

[1] Boshi Chen, Minxun Chen. Ac speed regulating system [M]. Beijing: Mechanical industry press, 2013

[2] Pian Zhou, Shuyun Wang, Lijiu Wang. The influence of rotor resistance variation of vector control [J]. Electrical automation.1998 (3):18-20

[3] Mingyu Wang, Chengyu Xian, Yaqian Hui. Induction motor vector control parameters off-line identification technology [J]. Transaction of China electrotechnical society, 2006(21):90-96

[4] Chao Cai, Guangdong Chen. A study on parameter estimation of induction motor using least square method [J]. Hubei: journal of Wuhan institute of chemical technology, 2003, 25 (2).

[5] Ruiming Fang, Hongguang Ma. Classification of Induction Machine Rotor Faults Based on Least Square Support Vector Machine [J]. Transaction of China electrotechnical society, 2006, 21(5).

[6] Xiwei Zhou. Asynchronous motor parameter identification based on EKF [D].Xian: Xian University of science and technology, 2003

[7] Zhongbo Peng, XueFeng Han, Zixue Du. Direct Torque Control for Electric Vehicle driver Motor Based on Extended Kalman Filter,[J] Vehicular Technology Conference Fall (VTC 2010-Fall), 2010 IEEE 72 nd

[8] A. Lalami, R. Wamkeue, I. Kamwa, M. Saad, J.J. Beaudoin. Unscented Kalman filter for non-linear estimation of induction machine parameters, [J] IET Electric Power Applications, Received on 31st January 2012.

[9] linBaek Kim, ByungKook Kim. Accurate States Estimation using Asynchronous Kalman Filter with Encoder Edges for TMRs,[J] International Conference on Control, Automation and Systems, Oct. 2023, 2013 in Kimdaejung Convention Center, Gwangju, Korea.

[10] Yin Yao, Lu Zhen. Based on model reference adaptive research of asynchronous motor vector control system [D]. Liaoning: Liaoning technical university, 2006

[11] V.Verma, M. J. Hossain, Member, IEEE, T. Saha, Senior Member, IEEE, C. Chakraborty, Senior Member, IEEE. Performance of MRAS Based Speed Estimators for Grid Connected Doubly fed Induction Machines during Voltage Dips, [J] Power and Energy Society General Meeting, 2012 IEEE.

[12] F. L. Mapelli, A. Bezzolato, D. Tarsitano. A Rotor Resistance MRAS Estimator for Induction Motor Traction Drive for Electrical Vehi cles, [J] Electrical Machines (ICEM), 2012 XXth International Conference on, 2-5 Sept. 2012.

[13] Ahmed S. Morsy and A. S. Abdel-khalik, Shehab Ahmed, Ahmed Massoud. Sensorless V/f Control with MRAS Speed Estimator for A Five-Phase Induction Machine under Open-Circuit Phase Faults, [J] 2013 IEEE GCC Conference and exhibition, November 17-20, Doha, Qatar.

[14] Tan Ma, Jin Zhao. The research on intelligent control of AC drive system based on neural network [D]. Huazhong University of science \& technology, 2009

[15] Zhang Dongdong, Luo Wenguang, Chen Wenhui, Xie Rongxian. Energy-saving Control Based on Neural Network Inverse Decoupling for Asynchronous Motors, [J] Power and Energy Engineering Conference (APPEEC), 2010 Asia-Pacific 
[16] Pham Thuong Cat, Le Hung Linh, and Minhtuan Pham. Speed Control of 3-Phase Asynchronous Motor Using Artificial Neural Network, [J] Control and Automation (ICCA), 2010 8th IEEE International Conference on.

[17] $\mathrm{Mu} \mathrm{Li}$, Peng Liu, Jiaoming Liu. Design of stray loss test system for three-phase asynchronous motor [J]. Motor and control applications,
2008, 35(8).

[18] Dongqi Zhu, Dewei Xu, Jianxin Jiang. Torque optimization analysis with nonlinear models for main path saturation of induction machines $[\mathrm{J}]$ Journal of Tsinghua university, 2001, 9 (9).

[19] Xinzhen Wu, Yanxiang Wang. Calculation of skin effect for double-gage rotor bar of the induction machine [J].proceeding of CSEE, 2003, 23(3). 